\title{
Estimation of fat-free mass in Asian neonates using bioelectrical impedance analysis
}

\author{
Mya-Thway Tint ${ }^{1,2}$, Leigh C. Ward ${ }^{3}$, Shu E. Soh ${ }^{4}$, Izzuddin M. Aris ${ }^{4}$, Amutha Chinnadurai ${ }^{5}$,
} Seang Mei Saw ${ }^{6}$, Peter D. Gluckman ${ }^{4,7}$, Keith M. Godfrey ${ }^{8}$, Yap-Seng Chong ${ }^{1,4}$, Michael S. Kramer ${ }^{9}$, Fabian Yap $^{10,11}$, Barbara Lingwood ${ }^{12}$ and Yung Seng Lee Le, $^{2,13 *}$

${ }^{1}$ Department of Obstetrics \& Gynaecology, National University of Singapore, 1E Kent Ridge Road, NUHS Tower Block, Level 12, Singapore, Singapore 119228

${ }^{2}$ Department of Pediatrics, Yong Loo Lin School of Medicine, National University of Singapore, 1E Kent Ridge Road, NUHS

Tower Block, Level 12, Singapore, Singapore 119228

${ }^{3}$ School Chemistry and Molecular Biosciences, The University of Queensland, Brisbane, QLD 4072, Australia

${ }^{4}$ Brenner Centre for Molecular Medicine, Singapore Institute for Clinical Sciences (SICS), Agency for Science, Technology and Research (A*STAR), 30 Medical Drive, Singapore, Singapore 117609

${ }^{5}$ Department of Neonatology, Khoo Teck Puat - National University Children's Medical Institute, National University Health System, 5 Lower Kent Ridge Road, Singapore, Singapore 119074

${ }^{6}$ Saw Swee Hock School of Public Health, Tabir Foundation Building, National University of Singapore, 12 Science Drive 2 , \#10-01, Singapore, Singapore 117549

${ }^{7}$ Liggins Institute, The University of Auckland, Private Bag 92019, Victoria Street West, Auckland 1142, New Zealand

${ }^{8}$ MRC Lifecourse Epidemiology Unit, NIHR Southampton Biomedical Research Centre, University of Southampton

E University Hospital Southampton NHS Foundation Trust, Southampton General Hospital, MP 218, Tremona Road, Southampton SO16 6YD, UK

${ }^{9}$ Departments of Pediatrics and of Epidemiology, Biostatistics and Occupational Health, McGill University Faculty of Medicine, Purvis Hall, 1020 Pine Ave, West Montreal, QC H3A 1A2, Canada

${ }^{10}$ Department of Pediatric Endocrinology, KK Women's and Children's Hospital, 100 Bukit Timah Road, Singapore, Singapore 229899

${ }^{11}$ Duke-NUS Graduate Medical School, Lee Kong Chian School of Medicine, Novena Campus, 11 Mandalay Road, Singapore, Singapore 308232

${ }^{12}$ UQ Centre for Clinical Research, The University of Queensland, Royal Brisbane E Women's Hospital Campus, Building 71/918, Herston, QLD 4029, Australia

${ }^{13}$ Division of Pediatric Endocrinology and Diabetes, Khoo Teck Puat - National University Children's Medical Institute, National University Health System, 5 Lower Kent Ridge Road, Singapore, Singapore 119074

(Submitted 3 September 2015 - Final revision received 15 December 2015 - Accepted 21 December 2015 - First published online 9 February 2016)

\section{Abstract}

The aims of this study were to develop and validate a prediction equation of fat-free mass (FFM) based on bioelectrical impedance analysis (BIA) and anthropometry using air-displacement plethysmography (ADP) as a reference in Asian neonates and to test the applicability of the prediction equations in an independent Western cohort. A total of 173 neonates at birth and 140 at two weeks of age were included. Multiple linear regression analysis was performed to develop the prediction equations in a two-third randomly selected subset and validated on the remaining one-third subset at each time point and in an independent Queensland cohort. FFM measured by ADP was the dependent variable, and anthropometric measures, sex and impedance quotient $\left(\mathrm{L}^{2} / \mathrm{R}_{50}\right)$ were independent variables in the model. Accuracy of prediction equations was assessed using intra-class correlation and Bland-Altman analyses. $\mathrm{L}^{2} / \mathrm{R}_{50}$ was the significant predictor of FFM at week two but not at birth. Compared with the model using weight, sex and length, including $\mathrm{L}^{2} / \mathrm{R}_{50}$ slightly improved the prediction with a bias of $0.01 \mathrm{~kg}$ with $2 \mathrm{sD}$ limits of agreement (LOA) $(0 \cdot 18,-0 \cdot 20)$. Prediction explained $88.9 \%$ of variation but not beyond that of anthropometry. Applying these equations to the Queensland cohort provided similar performance at the appropriate age. However, when the Queensland equations were applied to our cohort, the bias increased

Abbreviations: ADP, air-displacement plethysmography; BIA, bioelectrical impedance analysis; FFA, fat-free mass; FM, fat mass; GUSTO, Growing Up in Singapore Towards Healthy Outcomes; S, sex; L, length; LOA, limits of agreement; TBW, total body water; W, weight.

* Corresponding author: Associate Professor Y. S. Lee, fax +65 67797 486, email yung_seng_lee@nuhs.edu.sg 
slightly but with similar LOA. BIA appears to have limited use in predicting FFM in the first few weeks of life compared with simple anthropometry in Asian populations. There is a need for population- and age-appropriate FFM prediction equations.

\section{Key words: Bioelectrical impedance analysis: Air-displacement plethysmography: Validation: Asian neonates}

Research on developmental origins of health and disease has pointed to the importance of body size and composition at birth, which reflect the adaptation of the fetus to its intra-uterine environment, and is linked to the risk of subsequent metabolic diseases $^{(1)}$. Neonatal body composition has been a focus for many research studies as it may be a modifiable factor for health and diseases later in life ${ }^{(2)}$. Body composition can be measured by a variety of methods, which differ in accuracy, feasibility, cost and complexity. However, some methods are not suitable for neonates, including under-water weighing, stable isotope dilution and dual-energy X-ray absorptiometry (DXA), whereas others methods (such as MRI) are limited by their cost, especially for large epidemiological studies.

The measurement of body composition in neonates or infants is challenging, as the distribution of fluid in the body changes rapidly during the first few days of life, with $5-10 \%$ reduction in body weight attributable to the change in total body water (TBW) and body composition ${ }^{(3,4)}$. In addition, highly accurate techniques (e.g. MRI, stable isotope dilution) in neonates and infants generally require high compliance from the subject. This can be difficult to achieve in neonates and infants. Air-displacement plethysmography (ADP) for healthy infants has been validated in several studies using the ${ }^{2} \mathrm{H}$ dilution method for body water and a four-compartment body composition model as the reference methods ${ }^{(5-7)}$. ADP does not require the infant to be restrained during the 2-min measurement. However, the infant ADP device is expensive, large and not readily portable and generally not available outside of major hospitals and research facilities. Therefore, an inexpensive, portable and reliable method to measure body composition is clearly required at this age.

Bioelectrical impedance analysis (BIA) is a simple, noninvasive and useful method for estimating body composition in epidemiological and clinical research ${ }^{(8)}$. BIA measures impedance of the body to an imperceptible, harmless electric current transmitted through electrodes placed on the hands and the feet. Impedance $(\mathrm{Z})$ of a conductor is proportional to $\mathrm{L}^{2} / \mathrm{Z}$. Thus, impedance of the whole body can be used to estimate the volume of TBW in the aqueous tissue compartments. Fat-free mass (FFM) can be calculated from TBW by using a hydration fraction for FFM, usually assumed to be $0.732^{(9)}$. Fat mass (FM) can be estimated by subtracting FFM from body weight.

As BIA was first introduced as a method for estimating body composition, many studies have demonstrated its validity to measure body water in healthy populations of older children and adults with normal fluid distribution ${ }^{(8,10-17)}$. However, research on its usefulness for predicting body composition in neonates is limited, especially in Asians. Although a few small studies have reported the use of BIA in infants, most of them have not compared the performance of equations developed from BIA neither with that of simple anthropometry nor did they use an independent validation group ${ }^{(18-21)}$. In addition, the studies were on infants requiring intensive care or on low birth weight infants in whom the body composition profile may be different from that of healthy infants. Lingwood et $a l^{(22)}$ developed prediction equations for FFM based on BIA in a cohort of seventy-seven healthy infants in the first few months of life, and reported that the contribution of the BIA parameter in their model was not statistically significant and did not improve the prediction over that using weight alone until their study infants reached 3 months of age. In a recent study on predicting FFM using BIA reference to that of ADP also suggested the potential use of BIA in infants, and the subjects used to develop the prediction equation were of mixed age range that is, from 0 to 6 months ${ }^{(23)}$. These studies on predicting FFM in infants using impedance from BIA were conducted in the Western population, and thus may not necessarily be applicable to the Asian population. A prediction equation for FFM using BIA in Asian infants would be a valuable tool, especially in large cohorts or longitudinal cohort studies.

Our aims were to develop a prediction equation for FFM during the early neonatal period based on BIA and to validate that prediction using the ADP device, PEA POD infant body composition system, in Asian neonates. The applicability of this equation will also be tested in the independent validation group in this cohort as well as in an independent Western cohort of children from a study conducted at the University of Queensland.

\section{Methods \\ Study design and setting}

The neonates were participants of Growing Up in Singapore Towards Healthy Outcomes (GUSTO), a prospective birth cohort study in Singapore ${ }^{(24)}$. Pregnant women attending maternity units of two major public hospitals in Singapore, the KK Women's and Children's Hospital (KKH) and National University Hospital (NUH), were recruited in their first trimester between June 2009 and September 2010. All the participants were Singapore citizens or permanent residents, intended to deliver either in KKH or NUH and to reside in Singapore for the next 5 years. Both participant and her partner were of Chinese, Malay or Indian ethnicity with homogeneous parental ethnic background. Participants receiving chemotherapy or psychotropic drugs and those having type I diabetes mellitus were excluded. Recruited women were followed-up throughout pregnancy and delivery, and their children were followed-up postnatally.

\section{Subjects}

Participating neonates were born between November 2009 and May 2011 to GUSTO mothers. A total of 173 healthy singleton 
neonates who completed the BIA and ADP measurements at birth (0-3d), and 140 who completed them at week 2 (5-17 d), were included in this analysis. In total, fifty-two neonates were tested at both ages. Most neonates were born at term, although four neonates in each group were born at 35-37 completed weeks of gestation

\section{Ethics}

Study ethics approvals were obtained from the Centralized Institutional Review Board, SingHealth and Institutional Review Board of the National Health Care Group of Singapore.

\section{Anthropometry}

All anthropometric measurements at birth were carried out within $24 \mathrm{~h}$ after delivery (median: $1 \mathrm{~d}$ ) and at week 2 (median: $10 \mathrm{~d})$, respectively. The weight (W) of the neonate was measured using an integrated scale in the PEA POD infant body composition system. Recumbent length (L) was measured to the nearest $0.1 \mathrm{~cm}$ using a SECA infant mat (SECA 210 Mobile Measuring Mat; SECA Corp.). Recumbent length was measured in duplicate for reliability, and a third measurement was performed if the difference between the first two measurements was $>1 \mathrm{~cm}$. The average of the 2 or 2 closest of the 3 measurements was used for the analysis.

\section{Body composition measurement by PEA POD Infant body composition system}

The PEA POD Infant Body Composition System version 3.1.0 (Cosmed) was used to measure body composition - that is, FM and FFM. The system was calibrated each day before measuring the neonates. A cylinder with known volume was used to calibrate the chamber, and a $2-\mathrm{kg}$ weight was used to calibrate the scale. Clothing was removed and a tight-fitting cap was placed on the head to minimise the amount of air trapped in the hair. Items on the neonate that could not be removed - for example, the umbilical clamp or the hospital identification bracelet - were used to tare the scale for body weight and volume measurements. The neonate was then placed on the scale to measure body mass, and then placed inside the chamber for body volume measurement, which required approximately $2 \mathrm{~min}$. Weight and volume measurements by the PEA POD system are very precise with CV for repeated measurements of 0 and $0.02-0.09 \%$, respectively ${ }^{(5)}$. Infant percent body fat was computed by software integral to the PEA POD system. Body mass and body volume of the neonate were used to calculate body density $\left(D_{\mathrm{B}}\right)$. The raw $D_{\mathrm{B}}$ was adjusted for thoracic volume and surface area artefact. The values for the densities of FM and FFM were used to calculate \% fat and $\% \mathrm{FFM}^{(25,26)}$. The density of fat, $0.9007 \mathrm{~kg} / \mathrm{l}$, remains constant throughout life. This value is used by the PEA POD for fat density estimation ${ }^{(26)}$. Contrary to fat, the density of FFM changes from birth onwards. Thus, age- and sex-specific densities of FFM based on multi-compartment studies are used by the PEA POD ${ }^{(25,26)}$.
ADP is suggested to be more accurate for body fat measurement than $\mathrm{DXA}^{(27)}$. There is good agreement for within-subject measurements using the PEA POD with a mean differences of $<1 \%^{(7,28)}$. Likewise, there is good agreement between measurements of \% fat in term and preterm neonates using ADP and measurements using labelled water and a fourcompartment model. A study on forty-nine healthy infants demonstrated no significant difference in the mean $\%$ fat measured by ADP and that by the four-compartment model $\left(r^{2} 0.73 \text {, standard error of the estimate }(\mathrm{SEE})=3.7 \% \text { fat }\right)^{(7)}$. A similar study compared \% fat by ADP and $\mathrm{H}_{2}{ }^{18} \mathrm{O}$ dilution in seventy preterm infants and nine term infants and also reported good agreement $\left(r^{2} 0.63 \text {, SEE }=1.65 \% \text { fat }\right)^{(28)}$. The regression between the two different $\%$ fat measurements did not deviate significantly from the line of identity for both studies.

\section{Bioelectrical impedance analysis}

Bioimpedance was measured using the ImpediMed SFB7 (ImpediMed), a single-channel, tetra-polar bioimpedance spectroscopy device and its electrode 292-STE single-tab electrodes. The device measures resistance and reactance at 256 frequencies between 3 and $1000 \mathrm{kHz}$. We chose to use resistance at $50 \mathrm{kHz}$ as this frequency is used in single-frequency analysers. Therefore, the prediction equation developed will be applicable to predict FFM in infants using the more common single-frequency analysers.

Neonates were placed in the supine position. Insulating materials (e.g. thin cotton blanket) were used to prevent skinto-skin contact among the body parts. Sense electrodes were placed on the dorsum of the wrist and dorsum of the ankle at the level of the styloid process and the medial malleolus. Source electrodes were placed on the palm and sole over the metacarpals and metatarsals. Good connection between electrodes and the lead as well as skin contact of the electrodes were ensured. Ten consecutive BIA measurements were completed within $2 \mathrm{~min}$.

\section{Statistical analysis}

A random number generator was used to divide the subjects at each study visit (birth and week 2) into two groups: a model development group and a model validation group. The model development group included approximately two-thirds of the subjects and was used to develop prediction equations for FFM ( $n 116$ and 96 for birth and week 2, respectively). The model validation group comprised approximately one-third of the subjects ( $n 57$ and 46 at birth and week 2, respectively). FFM prediction equations based on BIA or simple anthropometry developed from 'model development groups' were applied to model validation groups. Subsequently, these predicted FFM were compared with FFM measured by $\mathrm{ADP}\left(\mathrm{FFM}_{\mathrm{ADP}}\right)$ at respective time points.

For prediction of FFM, either simple anthropometric measurements alone or in combination with the impedance quotient, $\mathrm{L}^{2} / \mathrm{R}_{50}\left(\mathrm{~cm}^{2} / \Omega\right)$, were used as predictors; $\mathrm{R}_{50}$ is the resistance at $50 \mathrm{kHz}$ and was used for all analyses. In the model development group, the prediction equation for FFM was 
developed by multiple linear regression analysis using $\mathrm{FFM}_{\mathrm{ADP}}$ as the dependent variable; predictors were $\mathrm{W}(\mathrm{kg})$, sex (S); ( male $=1$, female $=2$ ) together with $\mathrm{L}(\mathrm{cm})$ alone or $\mathrm{L}^{2} / \mathrm{R}_{50}$. Weight, length and sex were used in the prediction as these are significant predictors at least at one of the 2 time points (for length and sex). In addition, weight and length reflect the body size of the neonate. Sex was included as it is well accepted that there is sex difference in body composition; $\mathrm{R}_{50}$ is the resistance at $50 \mathrm{kHz}$ and was used for all analyses, and $50 \mathrm{kHz}$ is the frequency most commonly used in single-frequency impedance analysers.

Standardised regression coefficients were used to assess the independent contribution of each variable to the dependent variable (FFM). The developed prediction equation was then used to derive FFM in the validation group within the GUSTO cohort as an independent assessment of the performance of the prediction equation.

Agreement between $\mathrm{FFM}_{\mathrm{ADP}}$ and the predicted FFM by GUSTO equation ( $\mathrm{FFM}_{\mathrm{GUSTO}}$ ) either using the impedance quotient $\left(\mathrm{W}+\mathrm{S}+\mathrm{L}^{2} / \mathrm{R}_{50}\right)$ or simple anthropometry $(\mathrm{W}+\mathrm{S}+\mathrm{L})$ was assessed using the intra-class correlation coefficient (ICC). Bland-Altman analysis was then used to compare FFM $_{\mathrm{ADP}}$ and FFM derived from prediction equations. The bias or mean difference of FFM between the two methods was used to determine underestimation (negative bias) or overestimation (positive bias) of the prediction equation. The possible extent of the variation was determined by limits of agreement (LOA) (mean of differences (SD 1.96)) in which the agreement between two methods would lie in $95 \%$ of the repeated samples. The slope of the regression line defined whether there is a systematic variation of the difference with the mean of FFM values by two methods. Analysis was carried out using IBM SPSS 22 and MedCalc version 15 (MedCalc Software). Scattered plots and Bland-Altman plots were produced using MedCalc version 15 .

The GUSTO prediction equations developed at birth and week 2 ( FFM $\left._{\text {GUSTO}}\right)$ were also applied to an independent cohort from the University of Queensland to cross-validate the performance of the developed prediction equation in an independent Western population. This Queensland cohort included seventy-seven neonates at birth, fifty-four at 6 weeks, fifty-five at 3 months and fifty-three at 4.5 months of age ${ }^{(22)}$. Intra-class correlations between $\mathrm{FFM}_{\mathrm{ADP}}$ and $\mathrm{FFM}_{\mathrm{GUSTO}}$ in the Queensland cohort, as well as bias and LOA, were compared with correlations between $\mathrm{FFM}_{\mathrm{ADP}}$ and predicted FFM using the Queensland cohort's own equation developed at birth.

\section{Results}

Table 1 presents the characteristics of the neonates at birth and at week 2 after delivery. The physical characteristics and body composition of the neonates were not different in the model development and validation groups at either time point.

Resistance was negatively associated with $\mathrm{FFM}_{\mathrm{ADP}}$ both at birth and at week 2 . The strength of the association between $\mathrm{FFM}_{\mathrm{ADP}}$ and $\mathrm{R}_{50}$ was low at birth $(r-0.204, P=0.007)$ but stronger at week $2(r-0.438, P<0 \cdot 001)$. The correlations between $\mathrm{FFM}_{\mathrm{ADP}}$ and weight were $r 0.947$ and 0.946 (both $P<0.001)$ and between $\mathrm{FFM}_{\mathrm{ADP}}$ and length were $r 0.750$ and 0.753 (both $P<0.001$ ) at birth and week 2 , respectively.

Table 1. Characteristics of the study subjects

(Numbers and percentages; mean values and standard deviations)

\begin{tabular}{|c|c|c|c|c|c|c|c|c|c|c|}
\hline & \multicolumn{5}{|c|}{ Birth (n 173) } & \multicolumn{5}{|c|}{2 weeks after delivery $(n 140)$} \\
\hline & \multicolumn{2}{|c|}{$\begin{array}{l}\text { Model development } \\
\text { group ( } n 116)\end{array}$} & \multicolumn{2}{|c|}{ Validation group ( $n 57$ ) } & \multirow[b]{2}{*}{$P$} & \multicolumn{2}{|c|}{$\begin{array}{l}\text { Model development } \\
\text { group }(n \text { 94) }\end{array}$} & \multicolumn{2}{|c|}{ Validation group ( $n$ 46) } & \multirow[b]{2}{*}{$P$} \\
\hline & $n$ & $\%$ & $n$ & $\%$ & & $n$ & $\%$ & $n$ & $\%$ & \\
\hline \multirow{8}{*}{$\begin{array}{l}\text { Sex } \\
\text { Male } \\
\text { Female } \\
\text { Ethnicity } \\
\text { Chinese } \\
\text { Malay } \\
\text { Indians } \\
\text { Age groups } \\
\text { Age group I } \\
\text { Age group II } \\
\text { Age group III }\end{array}$} & $\begin{array}{l}52 \\
64\end{array}$ & $\begin{array}{l}44.8 \\
55 \cdot 2\end{array}$ & $\begin{array}{l}32 \\
25\end{array}$ & $\begin{array}{l}56 \cdot 1 \\
43 \cdot 9\end{array}$ & 0.162 & $\begin{array}{l}45 \\
49\end{array}$ & $\begin{array}{l}47.9 \\
52 \cdot 1\end{array}$ & $\begin{array}{l}30 \\
16\end{array}$ & $\begin{array}{l}65.2 \\
34.8\end{array}$ & 0.053 \\
\hline & & & & & \multirow[t]{3}{*}{0.179} & & & & & \multirow[t]{3}{*}{0.580} \\
\hline & $\begin{array}{l}59 \\
36\end{array}$ & $\begin{array}{l}50 \cdot 9 \\
31 \cdot 0\end{array}$ & $\begin{array}{l}21 \\
21\end{array}$ & $\begin{array}{l}36 \cdot 8 \\
36 \cdot 8\end{array}$ & & $\begin{array}{l}32 \\
43\end{array}$ & $\begin{array}{l}34 \cdot 0 \\
45 \cdot 7\end{array}$ & $\begin{array}{l}20 \\
18\end{array}$ & $\begin{array}{l}43.5 \\
39.1\end{array}$ & \\
\hline & 21 & $18 \cdot 1$ & 15 & $26 \cdot 3$ & & 19 & $20 \cdot 2$ & 8 & $17 \cdot 4$ & \\
\hline & & & & & & & & & & \\
\hline & $\begin{array}{l}85 \\
16\end{array}$ & $\begin{array}{l}73 \cdot 3 \\
13 \cdot 8\end{array}$ & $\begin{array}{r}38 \\
9\end{array}$ & $\begin{array}{l}66 \cdot 7 \\
15 \cdot 8\end{array}$ & \multirow[t]{2}{*}{0.647} & $\begin{array}{r}7 \\
81\end{array}$ & $\begin{array}{r}7.4 \\
86.2\end{array}$ & $\begin{array}{r}3 \\
42\end{array}$ & $\begin{array}{r}6.5 \\
91.3\end{array}$ & \multirow[t]{2}{*}{1.000} \\
\hline & 15 & $12 \cdot 9$ & 10 & 17.5 & & 6 & $6 \cdot 4$ & 1 & $2 \cdot 2$ & \\
\hline & Mean & SD & Mean & SD & $P$ & Mean & SD & Mean & SD & $P$ \\
\hline Gestational age (weeks) & 38.9 & $1 \cdot 1$ & 38.8 & $1 \cdot 1$ & 0.480 & & & & & \\
\hline Age on the day of BIA and ADP (d) & 1.0 & 0.0 & 1 & 0.0 & 0.392 & $10 \cdot 0$ & $2 \cdot 0$ & $10 \cdot 0$ & $2 \cdot 0$ & 0.762 \\
\hline Weight $(\mathrm{kg})$ & 3.11 & 0.37 & $3 \cdot 15$ & 0.41 & 0.500 & $3 \cdot 20$ & 0.40 & $3 \cdot 20$ & 0.40 & 0.847 \\
\hline Recumbent length (cm) & $48 \cdot 2$ & $2 \cdot 0$ & 48.5 & 1.8 & 0.267 & $49 \cdot 7$ & 1.8 & $49 \cdot 7$ & 1.7 & 0.881 \\
\hline Percentage fat-free mass (\%) & $90 \cdot \overline{3}$ & 3.5 & $89 \cdot 3$ & 3.8 & 0.103 & $87 \cdot 8$ & 3.7 & 88.4 & 3.5 & 0.323 \\
\hline Percentage fat mass $(\%)$ & $9 \cdot 7$ & 3.5 & $10 \cdot 7$ & 3.8 & 0.103 & $12 \cdot 2$ & $3 \cdot 7$ & 11.6 & $3 \cdot 1$ & 0.332 \\
\hline Fat-free mass $(\mathrm{kg})$ & $2 \cdot 77$ & 0.30 & 2.77 & 0.29 & 0.958 & $2 \cdot 80$ & 0.31 & $2 \cdot 80$ & 0.35 & 0.912 \\
\hline Fat mass $(\mathrm{kg})$ & 0.30 & 0.13 & 0.34 & 0.15 & 0.094 & 0.40 & 0.15 & 0.38 & 0.15 & 0.439 \\
\hline
\end{tabular}

* Age group at birth: I: day 0, II: day 1, III: day 2-3. Age group at week 2: I: <1 week, II: 1-2 weeks, III: >2 weeks.

Significant difference $(P<0.05)$. $P$ values were based on between-group comparisons of two sample $t$ tests for continuous variables and $\chi^{2}$ test for categorical variables. 
Table 2. Multiple regression analysis of weight (W; $\mathrm{kg})$, sex $(\mathrm{S})$ and length $(\mathrm{L})$ or impedance quotients for predicting fat-free mass (FFM) in the model development group

\begin{tabular}{|c|c|c|c|c|c|c|c|c|}
\hline \multirow[b]{2}{*}{ Model } & \multirow[b]{2}{*}{ Predictive variables } & \multirow[b]{2}{*}{ Overall $r$} & \multirow[b]{2}{*}{$R^{2}$} & \multirow[b]{2}{*}{ Adjusted $R^{2}$} & \multicolumn{3}{|c|}{ Standardised coefficients } & \multirow[b]{2}{*}{ Prediction equations for FFM (kg) } \\
\hline & & & & & W (kg) & $\mathrm{S}$ & $\mathrm{L}(\mathrm{cm})$ or $\mathrm{L}^{2} / \mathrm{R}_{50}\left(\mathrm{~cm}^{2} / \Omega\right)$ & \\
\hline \multicolumn{9}{|c|}{ Birth } \\
\hline $\begin{array}{l}1 \\
2 \\
3 \\
4 \\
5 \\
6\end{array}$ & $\begin{array}{l}\mathrm{L}^{2} / R_{50} \\
W \\
W+S \\
W+S+L \\
W+S+L^{2} \\
W+S+L^{2} / R_{50}\end{array}$ & $\begin{array}{l}0.541 \\
0.949 \\
0.952 \\
0.952 \\
0.952 \\
0.952\end{array}$ & $\begin{array}{l}0.293 \\
0.901 \\
0.906 \\
0.906 \\
0.906 \\
0.906\end{array}$ & $\begin{array}{l}0.904 \\
0.903 \\
0.904 \\
0.903\end{array}$ & $\begin{array}{l}0.541^{\star *} \\
0.949^{\star *} \\
0.941^{\star *} \\
0.943^{\star \star} \\
0.914^{\star \star} \\
0.932^{\star \star}\end{array}$ & $\begin{array}{l}-0.077^{\star \star} \\
-0.078^{\star} \\
-0.071^{\star} \\
-0.074^{\star}\end{array}$ & $\begin{array}{r}-0.004 \\
0.038 \\
0.017\end{array}$ & $\begin{array}{l}1.527+0.319 L^{2} / R_{50} \\
0.386+0.775 W \\
0.478+0.769 W-0.047 S \\
0.502+0.771 W-0.047 S-0.001 L \\
0.396+0.747 W-0.043 S+0.00006 L^{2} \\
0.459+0.762 W-0.045 S+0.010 L^{2} / R_{50}\end{array}$ \\
\hline \multicolumn{9}{|c|}{ Week 2} \\
\hline $\begin{array}{l}1 \\
2 \\
3 \\
4 \\
5 \\
6\end{array}$ & $\begin{array}{l}\mathrm{L}^{2} / R_{50} \\
W \\
W+S \\
W+S+L \\
W+S+L^{2} \\
W+S+L^{2} / R_{50}\end{array}$ & $\begin{array}{l}0.769 \\
0.935 \\
0.936 \\
0.943 \\
0.943 \\
0.948\end{array}$ & $\begin{array}{l}0.592 \\
0.874 \\
0.876 \\
0.888 \\
0.889 \\
0.899\end{array}$ & $\begin{array}{l}0.873 \\
0.885 \\
0.885 \\
0.895\end{array}$ & $\begin{array}{l}0.769^{\star \star} \\
0.935^{\star \star} \\
0.934^{\star \star} \\
0.803^{\star \star} \\
0.800^{\star \star} \\
0.783^{\star \star}\end{array}$ & $\begin{array}{l}-0.040 \\
-0.035 \\
-0.036 \\
-0.027\end{array}$ & $\begin{array}{l}0.173^{\star \star} \\
0.177^{\star \star} \\
0.214^{\star \star}\end{array}$ & $\begin{array}{l}1.333+0.402 L^{2} / R_{50} \\
0.430+0.741 W \\
0.469+0.741 W-0.024 S \\
-0.660+0.637 W-0.022 S+0.029 L \\
0.058+0.634 W-0.022 S+0.0003 L^{2} \\
0.375+0.621 W-0.016 S+0.112 L^{2} / R_{50}\end{array}$ \\
\hline
\end{tabular}

Birth

Model development group. The linear regression analysis revealed that weight and sex are both significant predictors of FFM at birth (Table 2). Weight was the strongest contributor to the prediction of FFM. The standardised coefficient for $\mathrm{L}^{2} / \mathrm{R}_{50}$ was greater than that for $\mathrm{L}$ in the models, but contribution of $\mathrm{L}^{2} / \mathrm{R}_{50}$ was not significant in the model including weight and sex. Weight explained $90.6 \%$ of the variance in FFM at birth. Adding sex to the model resulted in minimal improvement in predicting FFM, whereas adding $\mathrm{L}$ or $\mathrm{L}^{2} / \mathrm{R}_{50}$ led to no improvement.

Validation group. The scatterplot for the associations between $\mathrm{FFM}_{\mathrm{ADP}}$ and predicted or $\mathrm{FFM}_{(\mathrm{W}+\mathrm{S}+\mathrm{L})}$ are shown in Fig. 1(a) and (b), respectively. The ICC between FFM $_{\mathrm{ADP}}$ and was 0.970 $(P<0 \cdot 001)$ and for FFM $(\mathrm{W}+\mathrm{S}+\mathrm{L})$ it was $0 \cdot 971(P<0 \cdot 001)$. Fig. 2 shows the Bland-Altman plots for the validation group. The plots show the mean of $\mathrm{FFM}_{\mathrm{ADP}}$ and predicted FFM either by $\mathrm{W}+\mathrm{S}+\mathrm{L}^{2} / \mathrm{R}_{50}$ (Fig. 2(a)) or $\mathrm{W}+\mathrm{S}+\mathrm{L}$ (Fig. 2(b)) on the $\mathrm{x}$-axis and the difference between the two methods on the $y$-axis. The mean bias of the predicted was $0.03 \mathrm{~kg}$ - that is, $0.7 \%$ of FFM at birth $(2.77 \mathrm{~kg})$. The LOA were 0.22 to $-0.16 \mathrm{~kg}$. The root mean square error (RMSE) of the prediction equation using $\mathrm{W}+\mathrm{S}+\mathrm{L}^{2} / \mathrm{R}_{50}$ at birth was $0 \cdot 10 \mathrm{~kg}$. The mean bias of FFM prediction by $\mathrm{W}+\mathrm{S}+\mathrm{L}$ was $0 \cdot 11 \mathrm{~kg}$, larger than that of the model using $\mathrm{W}+\mathrm{S}+\mathrm{L}^{2} / \mathrm{R}_{50}$. The LOA were +0.30 to $-0.08 \mathrm{~kg}$. RMSE for this prediction by $\mathrm{W}+\mathrm{S}+\mathrm{L}$ was $0 \cdot 15 \mathrm{~kg}$. No significant relationship was observed between the mean and the difference of measured $v$. predicted FFM.

\section{Week 2}

Model development group. Unlike the prediction at birth, the prediction models at week 2 revealed that weight and either length or $\mathrm{L}^{2} / \mathrm{R}_{50}$ were significant predictors of neonatal FFM at week 2 but sex was not (Table 2 ). Adding $\mathrm{L}^{2} / \mathrm{R}_{50}$ to the model explained $89.9 \%$ of the variance in FFM at week 2 in neonates compared with $87.4 \%$ with weight alone and $88.8 \%$ with $\mathrm{W}+\mathrm{S}+\mathrm{L}$.

Validation group. The scatterplots between $\mathrm{FFM}_{\mathrm{ADP}}$ and that predicted FFM by $\mathrm{W}+\mathrm{S}+\mathrm{L}^{2} / \mathrm{R}_{50}$ or $\mathrm{W}+\mathrm{S}+\mathrm{L}$ in the validation group are shown in Fig. 1(c) and (d), respectively. The ICC between the $\mathrm{FFM}_{\mathrm{ADP}}$ and and $\mathrm{FFM}_{(\mathrm{W}+\mathrm{S}+\mathrm{L})}$ were 0.963 and $0.966(P<0.001)$, respectively.

The Bland-Altman analysis shows that the mean bias of FFM ( $\mathrm{kg}$ ) at week 2 by ADP and $\mathrm{W}+\mathrm{S}+\mathrm{L}^{2} / \mathrm{R}_{50}$ was $-0.01 \mathrm{~kg}-$ that is, $0.3 \%$ of FFM at week $2(2.80 \mathrm{~kg})$. The LOA for the GUSTO equation at week 2 were $+0 \cdot 18$ to $-0 \cdot 20 \mathrm{~kg}$ (Fig. 3(a)). Bias for prediction of $\mathrm{FFM}_{(\mathrm{W}+\mathrm{S}+\mathrm{L})}$ was slightly larger $(-0.03 \mathrm{~kg}$, $0.9 \%$ of FFM). The LOA of this prediction were 0.15 to $-0.21 \mathrm{~kg}$ (Fig. 3(b)). RMSE for prediction was similar to prediction using $\mathrm{L}^{2} / \mathrm{R}_{50}$ at $0.096 \mathrm{~kg}$. No significant relationship was observed between the mean and the difference of measured $v$. predicted FFM.

Cross-validation with the independent cohort. The GUSTO prediction equations using simple anthropometry or $\mathrm{L}^{2} / \mathrm{R}_{50}$ were applied to an independent cohort from the University of Queensland. When GUSTO prediction equations at birth were applied to the Queensland cohort at birth (Table 3), the ICC, bias and LOA of the predictions were very close to those values obtained in own GUSTO cohort, and again inclusion of the impedance quotient did not improve the prediction. However, when the Queensland equations were applied to the GUSTO cohort, the bias increased slightly, although the LOA were similar.

When GUSTO predictions equation developed at 2 weeks were applied at 6 weeks in the Queensland cohort, the bias and LOA were slightly smaller compared with results using the Queensland 6-week equation. However, when the GUSTO 2-week equation was applied to the Queensland cohort at 
(a)

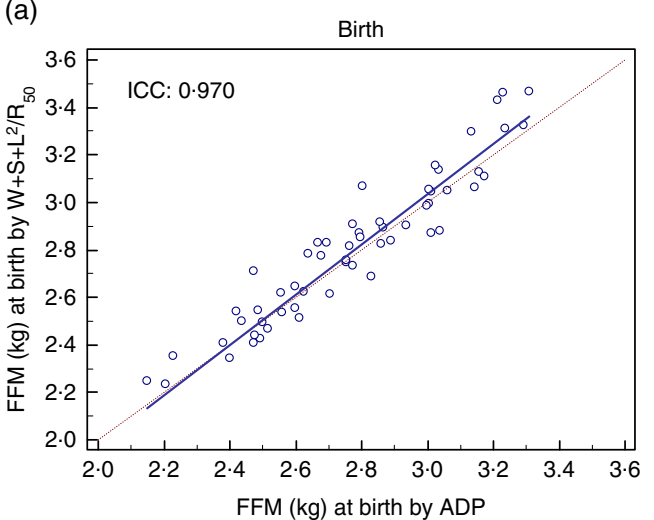

(b)

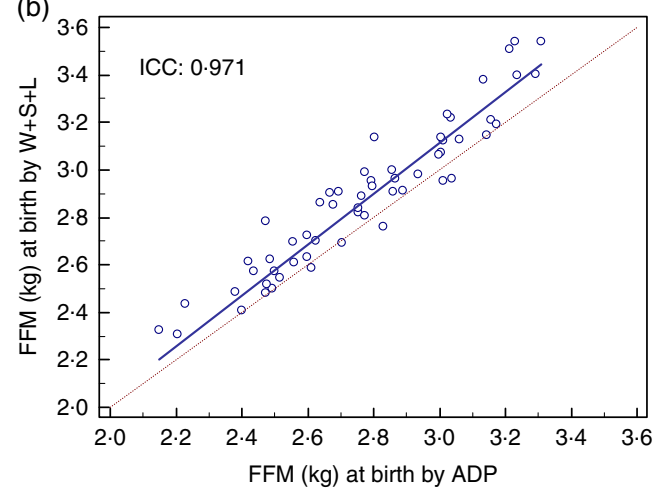

(c)

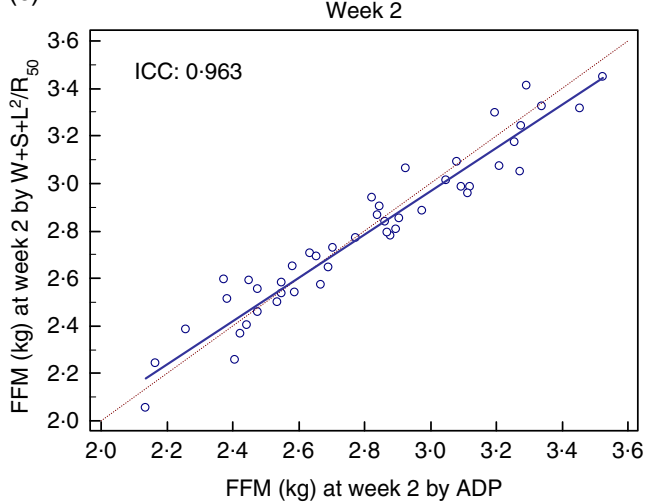

(d)

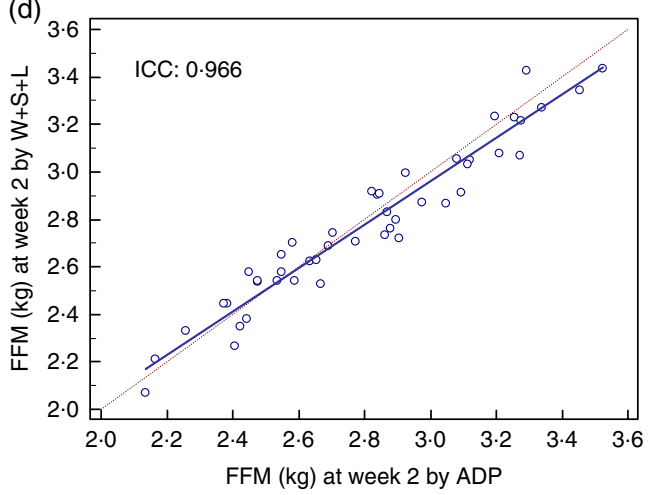

Fig. 1. Scatterplot of fat-free mass (FFM) (kg) of neonates measured by air-displacement plethysmography (ADP) and FFM derived from Growing Up in Singapore Towards Healthy Outcomes prediction equations based on weight $(W)$, sex $(S)$ and impedance quotient $\left(L^{2} / R_{50}\right)$ and $W, S$ and recumbent length $(L)$ in the validation group at birth $(\mathrm{a}$ and $\mathrm{b})$ and week $2(\mathrm{c}$ and $\mathrm{d})$. _ - Lines of identity. ICC, intra-class correlation coefficient.

3 months and 4.5 months of age, the bias was larger and LOA were wider compared with results using the Queensland's ageappropriate equations (Table 4). Agreement worsened with increasing age.

\section{Discussion}

A simple and reliable method is required to measure body composition in newborn infants participating in large epidemiological longitudinal studies ${ }^{(29)}$. Our findings add to the limited available evidence on the validity of BIA estimates of body composition in neonates. We developed prediction equations for FFM using BIA ( W $+\mathrm{S}+\mathrm{L}^{2} / \mathrm{R}_{50}$ ), as well as simple anthropometric measures $(\mathrm{W}+\mathrm{S}+\mathrm{L})$, and validated these against the criterion method ADP (PEA POD). At birth, we found that $\mathrm{L}^{2} / \mathrm{R}_{50}$ did not contribute significantly to the prediction of FFM. Unlike the findings at birth, the prediction then improved substantially over the subsequent week or two. At $1-2$ weeks of age, both $\mathrm{L}$ and $\mathrm{L}^{2} / \mathrm{R}_{50}$ became significant predictors of FFM. Their contributions to FFM prediction were similar and much greater than the non-significant contribution of sex at this age. The rapid changes in body water status and body composition in the first few days of life may impact on hydration status of FFM, thus confounding the conversion of TBW to $\mathrm{FFM}^{(30)}$. In the Queensland cohort, $\mathrm{L}^{2} / \mathrm{R}_{50}$ did not become a significant predictor of FFM until 4.5 months, and its contribution was similar to the significant contribution of $\operatorname{sex}^{(22)}$. In addition, this finding of significant contribution of $\mathrm{L}^{2} / \mathrm{R}_{50}$ in GUSTO may imply that the hydration status in Asian infants is different from the Western populations studied previously.

Although the $\mathrm{L}^{2} / \mathrm{R}_{50}$ contributed significantly to the prediction at 2 weeks of age, it did not appear to contribute much more than that provided by simple anthropometry. There is a debate in the literature as to whether $\mathrm{L}^{2} / \mathrm{R}_{50}$ performs better than simple anthropometry in predicting FFM. BIA is widely used in adults, adolescents and older children but much less frequently in infants. A few small studies have suggested that BIA is useful for estimating TBW or FFM in infants, but they were performed in low birth weight infants or infants requiring intensive care ${ }^{(30)}$, whose fluid distributions were likely to be different from healthy term infants. Moreover, those studies did not validate their equations in an independent group, nor did they compare prediction using BIA with the use of simple anthropometric measures alone ${ }^{(19,21)}$. Raghavan et al. ${ }^{(20)}$ reported high correlation between predicted TBW using BIA and that based on a dilution technique, but the prediction equation did not perform better than did weight alone. Tang et al. ${ }^{(21)}$ reported that weight and impedance index together improved an association $\left(r^{2}\right)$ slightly $v$. weight alone but they did not test that finding in a validation group. Lingwood et $a l^{(22)}$ concluded that it did not improve the prediction compared with simple anthropometry in infants younger than 3 months of age, whereas a slight improvement was present with the prediction using $\mathrm{L}^{2} / \mathrm{R}_{50}$ at 
(a)

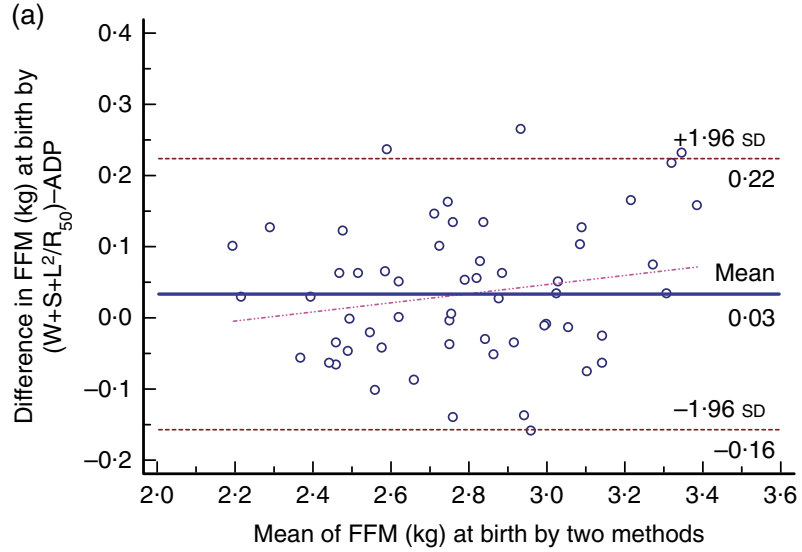

(b)

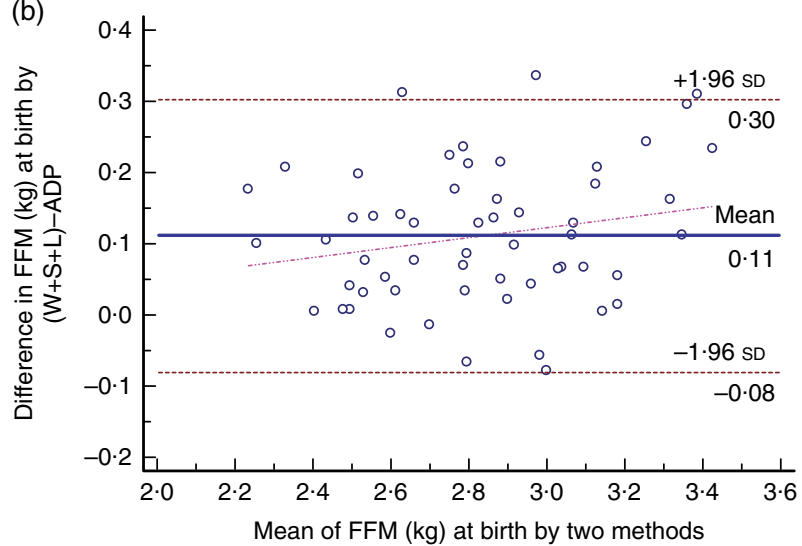

Fig. 2. Bland-Altman plots comparing fat-free mass (FFM) (kg) of neonates measured by air-displacement plethysmography (ADP) and from prediction equations based on weight $(W)$, sex $(S)$ and impedance quotient $\left(L^{2} / R_{50}\right)(a)$ and $\mathrm{W}, \mathrm{S}$ and recumbent length (L) (b) in the validation group at birth ( $n$ 57). _- The bias (mean difference) between the two methods; -..-.-..., the limits of agreement (mean bias (SD 1.96)); -........, the slope of the regression line between difference and mean of the measured and predicted FFM.

3 and 4.5 month of age. The study of Ethiopean infants by Wibaek et al. ${ }^{(23)}$, although with a wide age range of infants from $0-6$ months, also found that the $\mathrm{L}^{2} / \mathrm{R}_{50}$ improved prediction for infants older than 3 months of age. Therefore, our findings consistent with the previous findings suggest that BIA has limited value in very early life in predicting FFM, above and beyond that of anthropometry (weight and length) alone.

The failure of impedance measurements to improve the prediction of FFM at early infancy means that without DXA or $\mathrm{ADP}$, prediction is limited to anthropometric measures: weight, length and skinfold thickness (SFT). However, weight or length has inherent limitations for predicting body composition, because these measures do not differentiate between fat and lean mass. The use of weight alone assumes that FM and FFM have similar proportions over time and in different populations, which is not true. Even individuals with similar weight and length can have very different body composition ${ }^{(31)}$. Measurements of SFT have been shown to correlate with body fat measured in older children and infants ${ }^{(32-35)}$. A previous study in GUSTO showed that prediction of FM using subscapular SFT together with W, S and gestational age (GA), referenced to $\mathrm{FM}_{\mathrm{ADP}}$, only slightly improved prediction compared with (a)

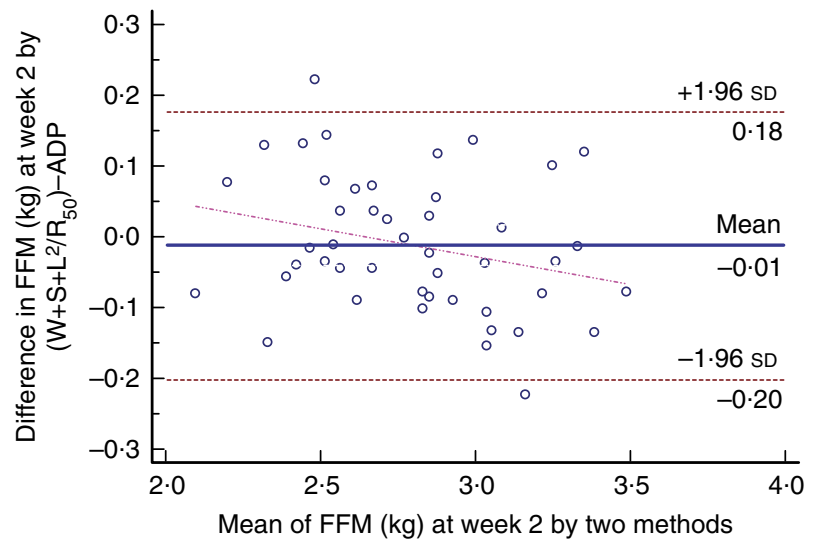

(b)

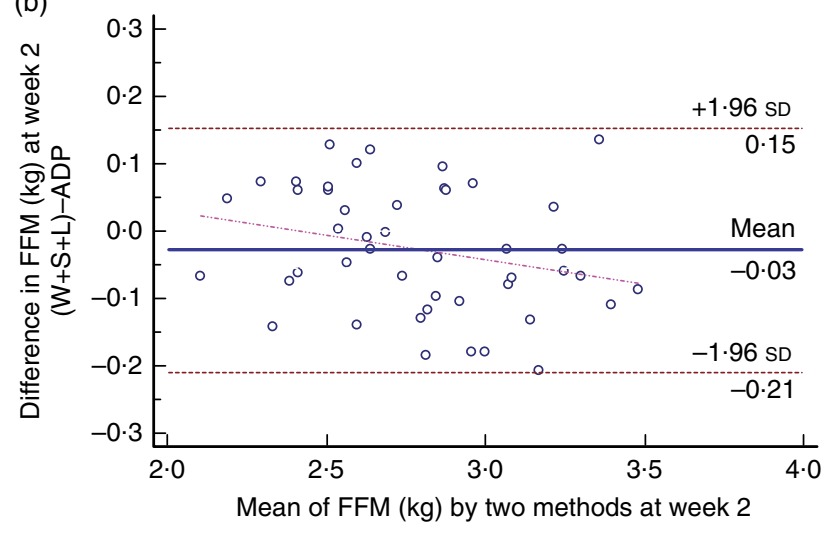

Fig. 3. Bland-Altman plots comparing fat-free mass (FFM) $(\mathrm{kg})$ of neonates measured by air-displacement plethysmography (ADP) and from prediction equations based on weight $(W)$, sex $(S)$ and impedance quotient $\left(L^{2} / R_{50}\right)(a)$ and $W, S$ and recumbent length $(L)(b)$ in the validation group at week 2 ( $n 46)$. $\ldots$, The bias (mean difference) between the two methods; -.-.-.-., the limit of agreement (mean bias (SD 1.96)); -........, the slope of the regression line between difference and mean of measured and predicted FFM.

prediction using $\mathrm{W}, \mathrm{S}$ and GA only $\left(r^{2} \quad 0 \cdot 811 v \cdot 0 \cdot 774\right)^{(36)}$. However, the validity of SFT in infants is being questioned due to rapid changes in hydration status and the variability in skinfold compressibility among neonates ${ }^{(13,37)}$. In addition, training of study team members, standardisation and quality control are a challenge, especially for large longitudinal studies.

Yajnik et al. ${ }^{(29,38)}$ have described the thin-fat phenotype of South Asian neonates: lower birth weight but greater adiposity, reflecting different intra-uterine trajectories in fat $v$. lean tissues. Studies on total or regional adiposity in Indian infants compared with European infants of UK suggested that Indian-born babies have greater adiposity compared with their Western counterparts $^{(29,39,40)}$. Other studies have shown that this phenotype at birth persists into childhood and later in life ${ }^{(41-43)}$. In addition, the first few weeks of life may be a critical period for the development of obesity later in life ${ }^{(44-48)}$. These findings may also reflect a different trajectory of FM and FFM growth in Asian populations. It would be of great value if a simple method could be developed to predict FFM beyond that of simple anthropometry during infancy.

When GUSTO prediction equations developed at birth and week 2 were applied to the respective age groups in the 
Table 3. Cross-validation of performance of fat-free mass prediction equations developed from the GUSTO and Queensland cohorts at birth

\begin{tabular}{|c|c|c|c|c|c|c|c|c|}
\hline Origin & $\begin{array}{l}\text { Age of } \\
\text { prediction }\end{array}$ & Parameters & Equation & Cohort applied & $\begin{array}{l}\text { Age group } \\
\text { applied }\end{array}$ & $\operatorname{Bias}(\mathrm{kg})^{\star}$ & $\operatorname{LOA}(\mathrm{kg})^{\star}$ & ICC \\
\hline \multirow[t]{2}{*}{ GUSTO } & \multirow[t]{2}{*}{ Birth } & \multirow[t]{2}{*}{$W+S$} & \multirow[t]{2}{*}{$0.478+0.769 W-0.047 S$} & GUSTO & Birth & 0.03 & $0.22,-0.16$ & 0.971 \\
\hline & & & & UQ & Birth & -0.03 & $0.20,-0.25$ & 0.966 \\
\hline UQ & Birth & $W+S$ & $0.864+0.682 W-0.093 S$ & GUSTO & Birth & 0.08 & $0.27,-0.10$ & 0.952 \\
\hline \multirow[t]{2}{*}{ GUSTO } & \multirow[t]{2}{*}{ Birth } & \multirow[t]{2}{*}{$W+S+L$} & \multirow[t]{2}{*}{$0.502+0.771 W-0.047 \mathrm{~S}-0.001 \mathrm{~L}$} & GUSTO & Birth & 0.11 & $0.30,-0.08$ & 0.940 \\
\hline & & & & UQ & Birth & -0.05 & $0.18,-0.27$ & 0.963 \\
\hline UQ & Birth & $W+S+L$ & $0.507+0.646 \mathrm{~W}-0.089 \mathrm{~S}+0.009 \mathrm{~L}$ & GUSTO & Birth & 0.06 & $0.24,-0.13$ & 0.963 \\
\hline \multirow[t]{2}{*}{ GUSTO } & \multirow[t]{2}{*}{ Birth } & \multirow[t]{2}{*}{$W+S+L^{2} / R_{50}$} & \multirow[t]{2}{*}{$0.459+0.762 \mathrm{~W}-0.045 \mathrm{~S}+0.010 \mathrm{~L}^{2} / \mathrm{R}_{50}$} & GUSTO & Birth & 0.03 & $0.22,-0.16$ & 0.970 \\
\hline & & & & UQ & Birth & -0.02 & $0.20,-0.24$ & 0.968 \\
\hline UQ & Birth & $\mathrm{W}+\mathrm{S}+\mathrm{L}^{2} / \mathrm{R}_{50}$ & $0.822+0.669 W-0.081 S+0.016 L^{2} / R_{50}$ & GUSTO & Birth & 0.08 & $0.26,-0.10$ & 0.954 \\
\hline
\end{tabular}

LOA, limit of agreement; ICC, intra-class correlation coefficient; GUSTO, Growing Up in Singapore Towards Healthy Outcomes; UQ, Queensland cohort.

* Bias and LOA were based on Bland-Altman analysis.

Table 4. Performance of fat-free mass prediction equations at week 2 and the Queensland's own age-appropriate equations at specific ages in the Queensland cohort

\begin{tabular}{|c|c|c|c|c|c|c|c|}
\hline Origin & Age of prediction & Parameters & Equation & Cohort applied & Age group applied & $\operatorname{Bias}(\mathrm{kg})^{\star}$ & LOA $(\mathrm{kg})^{\star}$ \\
\hline GUSTO & Week 2 & $W+S+L^{2} / R_{50}$ & $0.375+0.621 W-0.016 S+0.112 L^{2} / R_{50}$ & UQ & $\begin{array}{l}6 \text { weeks } \\
3 \text { months } \\
4.5 \text { months }\end{array}$ & $\begin{array}{l}-0.06 \\
-0.20 \\
-0.29\end{array}$ & $\begin{array}{l}0.32,-0.45 \\
0.25,-0.66 \\
0.42,-0.99\end{array}$ \\
\hline UQ & $\begin{array}{l}6 \text { weeks } \\
3 \text { months } \\
4.5 \text { months }\end{array}$ & $W+S+L^{2} / R_{50}$ & $\begin{array}{l}1.248+0.584 W-0.142 S+0.002 L^{2} / R_{50} \\
1.458+0.498 W-0.197 S+0.067 L^{2} / R_{50} \\
2.203+0.334 W-0.361 S+0.185 L^{2} / R_{50}\end{array}$ & UQ & $\begin{array}{l}6 \text { weeks } \\
3 \text { months } \\
4.5 \text { months }\end{array}$ & $\begin{array}{r}-0.10 \\
-0.03 \\
0.07\end{array}$ & $\begin{array}{l}0.32,-0.52 \\
0.41,-0.48 \\
0.59,-0.45\end{array}$ \\
\hline
\end{tabular}

LOA, limit of agreement; GUSTO, Growing Up in Singapore Towards Healthy Outcomes; UQ, Queensland cohort.

* Bias and LOA were based on Bland-Altman analysis.

Queensland cohort, the performance of the prediction equations seemed to be similar to its own GUSTO cohort. When the Queensland prediction equations developed at birth were applied to the same age group of the GUSTO cohort, the results were similar with a slightly larger bias and wider LOA. Therefore, although the performance of the GUSTO equation in the Queensland Cohort may suggest that prediction equations are transferrable, results from application of the Queensland equations to the GUSTO cohort suggest that FFM prediction equations are best used in the population in which they were originally developed.

When GUSTO FFM prediction equations developed at 2 weeks were applied to 6-week-old infants of the Queensland cohort, the bias and LOA were slightly smaller compared with results using the Queensland 6-week equation. However, when the GUSTO 2-week equations were applied to 3- and 4.5-month-old infants of the Queensland cohort, the bias was larger and LOA were wider than when using Queensland's equations at 3 months and 4.5 months of age, and agreement decreased with age. This finding implies that prediction equations are best applied in the age group for which they were developed.

A limitation of this study is that FFM density data produced by Fomon et al. ${ }^{(25)}$ and Butte et al. ${ }^{(26)}$ were based on Western populations. It is possible that FFM density of Asian infants will be different, which may impact on body composition data derived from the PEA POD.

In conclusion, BIA appears to have limited use in predicting FFM in the first few weeks of life compared with simple anthropometry. There is still a need for population- and age-appropriate FFM prediction equations. Future studies should assess the age at which electrical impedance provides a significant improvement over simple anthropometry in predicting body composition, especially in Asian populations.

\section{Acknowledgements}

This study acknowledges the contribution of the rest of the GUSTO study group, which includes the following: Pratibha Agarwal, Arijit Biswas, Choon Looi Bong, Birit F. P. Broekman, Shirong Cai, Jerry Kok Yen Chan, Yiong Huak Chan, Cornelia Yin Ing Chee, Helen Y. H. Chen, Yin Bun Cheung, Audrey Chia Chai Kiat Chng, Mary Foong-Fong Chong, Shang Chee Chong, Mei Chien Chua, Chun Ming Ding, Eric Andrew Finkelstein, Doris Fok, Marielle V. Fortier, Anne Eng Neo Goh, Yam Thiam Daniel Goh, Joshua J. Gooley, Wee Meng Han, Mark Hanson, Christiani Jeyakumar Henry, Joanna D. Holbrook, Chin-Ying Hsu, Hazel Inskip, Jeevesh Kapur, Kenneth Kwek, Ivy Yee-Man Lau, Bee Wah Lee, Ngee Lek, Sok Bee Lim, Yen-Ling Low, Iliana Magiati, Lourdes Mary Daniel, Michael J. Meaney, Cheryl Ngo, Krishnamoorthy Naiduvaje, Wei Wei Pang, Anqi Qiu, Boon Long Quah, Victor Samuel Rajadurai, Mary Rauff, Salome A. Rebello, Jenny L. Richmond, Anne Rifkin-Graboi, Lynette Pei-Chi Shek, Allan Sheppard, Borys Shuter, Leher Singh, Walter Stunkel, Lin Lin Su, Kok Hian Tan, Oon Hoe Teoh, Hugo P. S. van Bever, Rob M. van Dam, Inez Bik Yun Wong, P. C. Wong, George Seow Heong Yeo. All the authors thank the GUSTO study team, study participants, parents and their neonates for their valuable contribution in this study. 
This research is supported by the Singapore National Research Foundation under its Translational and Clinical Research (TCR) Flagship Programme and administered by the Singapore Ministry of Health's National Medical Research Council (NMRC), Singapore - NMRC/TCR/004-NUS/2008; NMRC/TCR/012-NUHS/2014. Additional funding was provided by the Singapore Institute for Clinical Sciences, Agency for Science Technology and Research (A*STAR), Singapore.

All the authors were involved in all parts of the study and approved the final version of the manuscript. S. M. S., K. M. G., P. D. G., Y.-S. C., F. Y., Y. S. L. designed and led the GUSTO study. M.-T. T. undertook the experimental studies, undertook the sample analyses and wrote the manuscript. L. C. W. and B. L. contributed to data analysis, statistical analysis, interpretation and manuscript preparation. L. C. W., B. L., M. S. K. and Y. S. L. provided important intellectual contribution to the revision of the manuscript. A. C., S. E. S. and I. M. A. contributed to the data analysis and revision of the manuscript.

P. D. G., K. M. G., Y. S. L. and Y.-S. C. have received re-imbursement for speaking at conferences sponsored by companies selling nutritional products. P. D. G., K. M. G. and Y. S. C. are part of an academic consortium that has received research funding from Abbott Nutrition, Nestle and Danone. No other potential conflicts of interest relevant to this article were reported. KMG is supported by the National Institute for Health Research through the NIHR Southampton Biomedical Research Centre and by the European Union's Seventh Framework Programme (FP7/2007-2013), project EarlyNutrition under grant agreement no 289346. L. C. W. provides consultancy services to ImpediMed Ltd. ImpediMed Ltd had no involvement in the conduct of this research or in the preparation of this manuscript.

\section{References}

1. Forsen T, Eriksson J, Tuomilehto J, et al. (2000) The fetal and childhood growth of persons who develop type 2 diabetes. Ann Inter Med 133, 176-182.

2. Ibanez L, Ong K, Dunger DB, et al. (2006) Early development of adiposity and insulin resistance after catch-up weight gain in small-for-gestational-age children. J Clin Endocrinol Metab 91, 2153-2158.

3. Podratz RO, Broughton DD, Gustafson DH, et al. (1986) Weight loss and body temperature changes in breast-fed and bottle-fed neonates. Clin Pediatr (Phila) 25, 73-77.

4. Lorenz JM (1997) Assessing fluid and electrolyte status in the newborn. National Academy of Clinical Biochemistry. Clin Chem 43, 205-210.

5. Urlando A, Dempster P \& Aitkens S (2003) A new air displacement plethysmograph for the measurement of body composition in infants. Pediatr Res 53, 486-492.

6. Ma G, Yao M, Liu Y, et al. (2004) Validation of a new pediatric air-displacement plethysmograph for assessing body composition in infants. Am J Clin Nutr 79, 653-660.

7. Ellis KJ, Yao M, Shypailo RJ, et al. (2007) Body-composition assessment in infancy: air-displacement plethysmography compared with a reference 4-compartment model. Am J Clin Nutr 85, 90-95.

8. Heitmann BL (1990) Evaluation of body fat estimated from body mass index, skinfolds and impedance. A comparative study. Eur J Clin Nutr 44, 831-837.
9. Sheng HP \& Huggins RA (1979) A review of body composition studies with emphasis on total body water and fat. Am J Clin Nutr 32, 630-647.

10. Kyle UG, Bosaeus I, De Lorenzo AD, et al. (2004) Bioelectrical impedance analysis - part I: review of principles and methods. Clin Nutr 23, 1226-1243.

11. Segal KR, Van Loan M, Fitzgerald PI, et al. (1988) Lean body mass estimation by bioelectrical impedance analysis: a foursite cross-validation study. Am J Clin Nutr 47, 7-14.

12. Danford LC, Schoeller DA \& Kushner RF (1992) Comparison of two bioelectrical impedance analysis models for total body water measurement in children. Ann Hum Biol 19, 603-607.

13. Davies PS \& Lucas A (1990) The prediction of total body fatness in early infancy. Early Hum Dev 21, 193-198.

14. Rush EC, Bristow S, Plank LD, et al. (2013) Bioimpedance prediction of fat-free mass from dual-energy X-ray absorptiometry in a multi-ethnic group of 2-year-old children. Eur J Clin Nutr 67, 214-217.

15. Eisenmann JC, Heelan KA \& Welk GJ (2004) Assessing body composition among 3- to 8-year-old children: anthropometry, BIA, and DXA. Obes Res 12, 1633-1640.

16. Rush EC, Puniani K, Valencia ME, et al. (2003) Estimation of body fatness from body mass index and bioelectrical impedance: comparison of New Zealand European, Maori and Pacific Island children. Eur J Clin Nutr 57, 1394-1401.

17. Kriemler S, Puder J, Zahner L, et al. (2009) Cross-validation of bioelectrical impedance analysis for the assessment of body composition in a representative sample of 6- to 13-year-old children. Eur J Clin Nutr 63, 619-626.

18. Dung NQ, Fusch G, Armbrust S, et al. (2007) Body composition of preterm infants measured during the first months of life: bioelectrical impedance provides insignificant additional information compared to anthropometry alone. Eur J Pediatr 166, 215-222.

19. Mayfield SR, Uauy R \& Waidelich D (1991) Body composition of low-birth-weight infants determined by using bioelectrical resistance and reactance. Am J Clin Nutr 54, 296-303.

20. Raghavan CV, Super DM, Chatburn RL, et al. (1998) Estimation of total body water in very-low-birth-weight infants by using anthropometry with and without bioelectrical impedance and H2[(18)O]. Am J Clin Nutr 68, 668-674.

21. Tang W, Ridout D \& Modi N (1997) Assessment of total body water using bioelectrical impedance analysis in neonates receiving intensive care. Arch Dis Childhood Fetal and neonatal edition 77, F123-F126.

22. Lingwood BE, Storm van Leeuwen AM, Carberry AE, et al. (2012) Prediction of fat-free mass and percentage of body fat in neonates using bioelectrical impedance analysis and anthropometric measures: validation against the PEA POD. Br J Nutr 107, 1545-1552.

23. Wibaek R, Kaestel P, Skov SR, et al. (2015) Calibration of bioelectrical impedance analysis for body composition assessment in Ethiopian infants using air-displacement plethysmography. Eur J Clin Nutr 69, 1099-1104.

24. Soh SE, Tint MT, Gluckman PD, et al. (2014) Cohort profile: Growing Up in Singapore Towards Healthy Outcomes (GUSTO) birth cohort study. Int J Epidemiol 43, 1401-1409.

25. Fomon SJ, Haschke F, Ziegler EE, et al. (1982) Body composition of reference children from birth to age 10 years. Am J Clin Nutr 35, 1169-1175.

26. Butte NF, Hopkinson JM, Wong WW, et al. (2000) Body composition during the first 2 years of life: an updated reference. Pediatr Res $\mathbf{4 7}, 578-585$.

27. Fields DA \& Goran MI (2000) Body composition techniques and the four-compartment model in children. J Appl Physiol 89, 613-620. 
28. Roggero P, Gianni ML, Amato O, et al. (2012) Evaluation of air-displacement plethysmography for body composition assessment in preterm infants. Pediatr Res 72, 316-320.

29. Yajnik CS, Fall CH, Coyaji KJ, et al. (2003) Neonatal anthropometry: the thin-fat Indian baby. The Pune Maternal Nutrition Study. Int J Obes Relat Metab Disord 27, 173-180.

30. Collins CT, Reid J, Makrides M, et al. (2013) Prediction of body water compartments in preterm infants by bioelectrical impedance spectroscopy. Eur J Clin Nutr 67, Suppl 1, S47-S53.

31. Yajnik CS \& Yudkin JS (2004) The Y-Y paradox. Lancet 363, 163.

32. Goran MI, Driscoll P, Johnson R, et al. (1996) Cross-calibration of body-composition techniques against dual-energy X-ray absorptiometry in young children. Am J Clin Nutr 63, 299-305.

33. Weststrate JA \& Deurenberg P (1989) Body composition in children: proposal for a method for calculating body fat percentage from total body density or skinfold-thickness measurements. Am J Clin Nutr 50, 1104-1115.

34. Sheng HP, Muthappa PB, Wong WW, et al. (1993) Pitfalls of body fat assessments in premature infants by anthropometry. Biol Neonate 64, 279-286.

35. Schmelzle HR \& Fusch C (2002) Body fat in neonates and young infants: validation of skinfold thickness versus dualenergy X-ray absorptiometry. Am J Clin Nutr 76, 1096-1100.

36. Aris IM, Soh SE, Tint MT, et al. (2013) Body fat in Singaporean infants: development of body fat prediction equations in Asian newborns. Eur J Clin Nutr 67, 922-927.

37. Lohman TG (1993) Advances in Body composition assessment. Med Sci Sports Exerc 25, 762.

38. Yajnik CS, Lubree HG, Rege SS, et al. (2002) Adiposity and hyperinsulinemia in Indians are present at birth. $J$ Clin Endocrinol Metab 87, 5575-5580.

39. Nightingale CM, Rudnicka AR, Owen CG, et al. (2011) Patterns of body size and adiposity among UK children of South Asian, black African-Caribbean and white European origin: Child Heart And health Study in England (CHASE Study). Int $J$ Epidemiol 40, 33-44.

40. Modi N, Thomas EL, Uthaya SN, et al. (2009) Whole body magnetic resonance imaging of healthy newborn infants demonstrates increased central adiposity in Asian Indians. Pediatr Res 65, 584-587.

41. Krishnaveni GV, Hill JC, Veena SR, et al. (2005) Truncal adiposity is present at birth and in early childhood in South Indian children. Indian Pediatr 42, 527-538.

42. Bavdekar A, Yajnik CS, Fall CH, et al. (1999) Insulin resistance syndrome in 8-year-old Indian children: small at birth, big at 8 years, or both? Diabetes $\mathbf{4 8}, 2422-2429$.

43. Dudeja V, Misra A, Pandey RM, et al. (2001) BMI does not accurately predict overweight in Asian Indians in northern India. Br J Nutr 86, 105-112.

44. Stettler N \& Iotova V (2010) Early growth patterns and long-term obesity risk. Curr Opin Clin Nutr Metab Care 13, 294-299.

45. Chandler-Laney PC, Gower BA \& Fields DA (2013) Gestational and early life influences on infant body composition at 1 year. Obesity 21, 144-148.

46. Andersen LG, Holst C, Michaelsen KF, et al. (2012) Weight and weight gain during early infancy predict childhood obesity: a case-cohort study. Int J Obes (Lond) 36, 1306-1311.

47. Stettler N, Stallings VA, Troxel AB, et al. (2005) Weight gain in the first week of life and overweight in adulthood: a cohort study of European American subjects fed infant formula. Circulation 111, 1897-1903.

48. Botton J, Heude B, Maccario J, et al. (2008) Postnatal weight and height growth velocities at different ages between birth and $5 \mathrm{y}$ and body composition in adolescent boys and girls. Am J Clin Nutr 87, 1760-1768. 